\begin{tabular}{|l|l|}
\hline Running head: & $\begin{array}{l}\text { The effects of salivas on occlusal forces } \\
\text { Article category: }\end{array}$ \\
\hline Authors: & $\begin{array}{l}\text { Original research } \\
\text { Thomas R. Katona } \\
\text { George J. Eckert }\end{array}$ \\
\hline Affiliations: & $\begin{array}{l}\text { McCrea \& Katona: } \\
\text { Department of Orthodontics and Oral Facial Genetics, Indiana University } \\
\text { School of Dentistry, Indianapolis, USA } \\
\text { Eckert: } \\
\text { Department of Biostatistics, Indiana University School of Medicine, Indianapolis, } \\
\text { USA }\end{array}$ \\
\hline Correspondence: & $\begin{array}{l}\text { Dr. T. R. Katona } \\
\text { Department of Orthodontics and Oral Facial Genetics } \\
\text { Indiana University School of Dentistry } \\
1121 \text { W. Michigan St., Indianapolis, IN 46202, USA } \\
\text { tkatona@iu.edu }\end{array}$ \\
\hline
\end{tabular}

This is the author's manuscript of the article published in final edited form as:

McCrea, E. S., Katona, T. R., \& Eckert, G. J. (2015). The effects of salivas on occlusal forces. Journal of Oral Rehabilitation, 42(5), 348-354. http://doi.org/10.1111/joor.12260 


\section{The effects of salivas on occlusal forces}

SUMMARY Contacting surfaces of opposing teeth produce friction that, when altered, changes the contact force direction and/or magnitude. Since friction can be influenced by several factors, including lubrication and the contacting materials, the aim of this study is to measure the occlusal load alterations experienced by teeth with the introduction of different salivas and dental restorative materials. Pairs of molar teeth were set into occlusion with a weighted maxillary tooth mounted onto a vertical sliding assembly and the mandibular tooth supported by a load cell. The load components on the mandibular tooth were measured with three opposing pairs of dental restorative materials (plastic denture, all-ceramic and stainless steel), four (human and 3 artificial) salivas, and 16 occlusal configurations. All lateral force component measurements were significantly different $(P<0.0001)$ from the dry (control) surface regardless of the crown material or occlusal configuration, while the effects of the artificial salivas compared to each other and to human saliva depended on the crown material.

KEYWORDS: dental occlusion, friction, saliva, occlusal force, lubrication, permanent dental restoration

\section{Introduction}

When teeth occlude, friction forces are produced at the contact points. These forces depend on the materials in contact and their environment (1). For example, porcelain-on-porcelain friction has been estimated to be three times that of enamel-on-enamel (2). Altering the friction changes the contact force magnitude and/or direction, and if these forces become excessive and/or misdirected (3) and therefore exceed physiologic tolerance, pathologic changes $(2,4)$, occlusal trauma or temporomandibular joint disorders may result (5).

Friction between occluding teeth is influenced by the quantity or quality of saliva and the presence of restorative materials (6). Lubrication is the property of a substance that reduces the friction between contacting surfaces and saliva provides a lubricating film on the surfaces of teeth $(6,7)$. Studies [Type here] 
have shown that some liquids reduce the friction between enamel surfaces, while others may increase it between enamel and restorative materials (8-11). Studies have confirmed that alterations in occlusion are multifactorial (12) and that friction and lubrication may play a role (13).

There is a gap in the literature about the effects of occlusal contact friction and its modification by liquids or the presence of restorative materials. Thus, the purpose of this study is to measure the occlusal load alterations experienced by teeth with different salivas and dental restorative materials.

\section{Materials and methods}

\section{Brief Description}

Two opposing molar teeth were mounted in a testing apparatus and set into occlusion (Fig. 1). As the maxillary tooth was lowered along a vertical slide onto the mandibular tooth (which was supported by a load cell), the 6 load components, Fig. 2, acting on the mandibular tooth were recorded by the load cell. The procedure was repeated with the teeth in various occlusal configurations, with or without (control) a saliva, and of three restorative materials.

\section{Experimental materials and methods}

Human saliva and three artificial substitutes currently on the market were used and compared to a control (dry) sample. The human saliva (IRB approved bio bank \#1105005588) was kept refrigerated, but at room temperature during data collection. The salivary substitutes were kept at room temperature. They were Moi-Stir ${ }^{\circledR}$ (Kingswood Labs, Indianapolis, IN), Mouth Kote ${ }^{\circledR}$ (Parnell Pharmaceuticals, San Rafael, $\mathrm{CA}$ ), and Oasis ${ }^{\circledR}$ (Oasis Consumer Healthcare, Cleveland, $\mathrm{OH}$ ). These were chosen for their different active ingredients, namely carboxymethylcellulose $(\mathrm{CMC})$ in Moi-Stir®, the Yerba Santa plant (a mucopolysaccharide) in Mouth Kote ${ }^{\circledR}$, and glycerin (35\%) in Oasis ${ }^{\circledR}$. The three crown materials were plastic denture teeth (Dentsply Portrait IPN ${ }^{3} 33$ degrees), esthetic all-ceramic crowns (IPS Empress ${ }^{\circledR}$ CAD), and stainless steel crowns (3M $\left.{ }^{\mathrm{TM}} \mathrm{ESPE}^{\mathrm{TM}}\right)$.

\section{Instrument and measurement}

The apparatus (Fig. 1) included a base shelf with a vertical support that were bolted onto an MTS Bionix 858 (MTS Corp., Minneapolis, MN) testing machine. The maxillary tooth was weighted down to $15 \mathrm{~N}$, 
which is within the range of the average biting force in the molar region [9-180 N (14)] and within the limits of the load cell (Gamma Transducer, SI-65-5, ATI Industrial Automation, Apex, NC) that supported the mandibular tooth. A precision slide (Mini-Guide, Double Carriage, Model \#SEBS 9BUU2-195, Nippon Bearing Co, Japan) on the vertical support guided the maxillary tooth, and a pivoting assembly allowed the slide to be tipped in all directions, Fig. 1A.

The MTS testing machine was used to lower (sinusoidal displacement control, $0.2 \mathrm{~Hz}$ and $4.0 \mathrm{~mm}$ amplitude) the maxillary tooth with a 17 inch \#16 double-loop jack chain (generic). The load cell measured $($ at $100 \mathrm{~Hz})$ the force $F_{x}, F_{y}$ and $F_{z}(0-65 \pm 0.2 N)$ and moment $M_{x}, M_{y}$ and $M_{z}(0-5000 \pm 0.9$ $\mathrm{N}-\mathrm{mm}$ ) components acting on the mandibular tooth (Fig. 2) with the teeth in various occlusal configurations (Fig. 3), with or without (control) a saliva. Three pairs of crown materials (denture plastic, ceramic and stainless steel) were tested.

The maxillary and mandibular denture teeth were attached with orthodontic resin into an acrylic tube and an enlarged (drilled about $1 \frac{1}{2}$ way down) hex coupling nut, respectively (Figs. $3 \mathrm{~A}$ and $\mathrm{B}$ ). 3M Unitek Multi-Cure Glass Ionomer Band Cement was used to attach the ceramic (Fig. 3C) and stainless steel (Fig. 3D) crowns onto ground-down screw head abutments.

\section{Data sets and data acquisition}

A data set (Table 1) consists of the 6 load components measured with opposing molars in one of the 4 occlusions (Class I, cross-bite, Class II or Class III; Fig. 3) and one of the maxillary angulations (Vertical, Mesial, Distal or Buccal).

The occlusal surfaces were cleaned with a 95.5\% Ethanol (200-proof Ethyl Alcohol) dipped gauze pad and dried with oil-free compressed air. The 6 load components measured with this dry surface constituted the first control (C1). Then, Moi-Stir (MS) was placed on the mandibular tooth with a disposable pipette and on the maxillary tooth by dipping it into a shallow cap. The load components were measured, the occlusal surfaces were cleaned again, and the $\mathrm{C} 2$ readings were obtained, and so on. Thus, a full sequence consisted of $\mathrm{C} 1 \rightarrow \mathrm{MS} \rightarrow \mathrm{C} 2 \rightarrow \mathrm{MK} \rightarrow \mathrm{C} 3 \rightarrow \mathrm{Oa} \rightarrow \mathrm{C} 4 \rightarrow \mathrm{HS} \rightarrow \mathrm{C} 5$. By repositioning the plywood base (Fig. 1A), this sequence was performed with all four molar relationships (Class I, I crossbite, II and III). 
All procedures described in the previous paragraph were conducted with 4 maxillary crown angulations (measured with the Clinometer + bubble app by Plaincode ${ }^{\mathrm{TM}}$ ) at $0^{\circ}$ (upright), $2^{\circ}$ mesial, $2^{\circ}$ distal and $2^{\circ}$ buccal, for a total of 16 data sets, each a different occlusal configuration (Table 1 ). All 16 data sets were obtained with three pairs (denture teeth, all-ceramic crowns and stainless steel crowns) of opposing restorative materials, or 48 sets of data.

\section{Statistical methods}

The difference from control regardless of direction, the absolute fold-change, AFC $=\left|\frac{\text { Product }- \text { Control }}{\text { Control }}\right|$, was calculated for each measurement. An AFC of zero indicates the same measurement as control, while an AFC of 1 indicates a 100\% change (i.e., twice as high or twice as low) from control. Wilcoxon signed rank tests were used to test for the significance of AFC, which determined whether the saliva had a significant effect compared to the dry surface. A linear mixed-effects model was used to determine whether the salivas affected the loads, with fixed effects for saliva (human, Moi-Stir, Mouth Kote, and Oasis), restoration type (denture plastic, ceramic and stainless steel), and their interaction, and random effects to correlate data within occlusal configuration for each restoration type and across restoration types. For all analyses, pair-wise comparisons were performed when the overall F-test for any difference was significant, using Fisher's Protected Least Significant Differences to control the overall significance level at $5 \%$. The ranks of the data were used in the analyses because of the non-normally distributed data.

\section{Results}

Analyses were conducted on lateral force components $F_{x}$ and $F_{y}$ that were linearly interpolated to the $F_{z}=$ $-13.0 \mathrm{~N}$ value. Moments $\left(M_{x}, M_{y}, M_{z}\right)$ were not considered because the positions of the occlusal surfaces relative to the load cell (i.e., the moment arms) impact the moments, whereas the force components are unaffected by apparatus geometry (15).

The intraclass correlation coefficients (ICCS) for the controls were 0.98 or higher for all measurements, confirming that each control (taken as a measurement alternating with each liquid) was consistent, thus verifying that the occlusal surface cleaning between salivas was effective. An absolute fold change (AFC) was used to detect differences regardless of the direction (positive or negative). The 
AFCs for $F_{x}$ and $F_{y}$ for all salivas and all occlusions were significantly different $(P<0.0001)$ than the drysurface control, Table 2. The salivas are compared with each other in Table 3.

\section{Discussion}

Clinically, all force and moment components must be considered, but, as noted above, focusing on the former is appropriate for the purposes of this study. All wet $F_{x}$ and $F_{y}$ were significantly different $(P<0.0001)$ from those with dry (control) surfaces (Table 2), regardless of crown material or occlusion. With denture teeth, Oasis ${ }$ produced $F_{x}$ and $F_{y}$ changes greater than Moi-Stir ${ }^{\circledR}$ and Mouth-Kote ${ }^{\circledR}(T a b l e$ 3). In contrast, with ceramic, $F_{x}$ and $F_{y}$ changed more with human saliva, Moi-Stir ${ }^{\circledR}$ and Mouth-Kote ${ }^{\circledR}$ than with Oasis ${ }^{\circledR}$. With stainless steel, $F_{y}$ changed more with Oasis ${ }^{\circledR}$ than with Mouth-Kote ${ }^{\circledR}$.

There is no evidence to suggest that good lubrication is clinically preferable to poor lubrication, so it is useful to compare the artificial salivas with human saliva, Table 3. With denture teeth, Oasis $®$ was the most similar to human saliva, while Moi-Stir ${ }^{\circ}$ and Mouth-Kote ${ }^{\circledR}$ produced significantly different force values. With ceramic, it was the opposite, and there were no significant differences with stainless steel crowns. It has been stated that mucin-based substitutes (e.g., Mouth Kote®) possess lubricating qualities comparable to human saliva (16). Our results indicate that that may be true with ceramic and stainless steel, but not with denture teeth. Thus, these results have potential clinical implications particularly for patients with xerostomia, various restorations and those using salivary substitutes.

Thus the salivas cause significant contact force differences that depend on the restorative materials. (There were no significant differences in the effects of the salivas with the Class I, II and III molar relationships and with the tipped maxillary tooth configurations.) Although the modifications in contact forces are attributable to dissimilar lubrication by the salivas, the results cannot be used to deduce if a specific saliva is a better, or worse, lubricant than another. Conversely, the lubricative ability of a saliva is not predictive of the associated contact force alterations. Although contact forces and lubrication are intimately related, the relationship is entirely unpredictable. (This unpredictability, is due to the nature of statically indeterminate systems.) Therefore, comparisons with salivary lubrication literature would be useless.

This study did not consider combinations of occluding surfaces (e.g, plastic/ceramic, plastic/stainless-steel, and ceramic/stainless-steel). And, typically, there can be more than one type of [Type here] 
contact surface on the same tooth, for example, with amalgam restorations. Lubrication by foods and drinks also has a role.

Quantitatively, the measurements depend on the unique stiffness of the testing apparatus. However, given the purposes of this study, that should not be considered as a shortcoming because, clinically, there is a huge range of flexibilities associated with healthy periodontia, periodontally compromised teeth, ankylosed teeth, implants, dentures, and so on.

It can be concluded that these findings have clinical implications whenever occlusal forces are involved. After all, the magnitudes of the lateral force components on the crown $\left(F_{x}\right.$ and $\left.F_{y}\right)$, which are generally considered to be destructive, were measured to be as high as $\sim 80 \%$ that of the occlusal $\left(\mathrm{F}_{z}\right)$ force (Moi-Stir ${ }^{\circledR}$ on ceramic crowns, Table 2). Our data demonstrate that saliva is one of the critical determinants of those lateral force magnitudes. Consider also the clinically desired axial alignment of occlusal forces. If attained, it would likely be ruined by any change in saliva. Another example is the relationship between athletic endurance training and oral health problems (17). Although changes in saliva are cited as contributing factors, the effect of those changes on friction is overlooked as a possible etiology (13).

This study clearly illustrates the complexity of occlusal contact force dependence on the interactions between occlusion, tooth materials and salivas. It is impossible to quantitatively define those relationships, however, the data demonstrate that changes in saliva have the potential to adversely, or beneficially, alter the mechanical environment in the masticatory system.

\section{Acknowledgements}

This study was partially supported by the Indiana University School of Dentistry (IUSD) Graduate Student Research Fund. Donations included stainless steel crowns by North Point Pediatric Dentistry, ceramic crowns by Dr. Paul Reifeis, and human saliva by IUSD Oral Health Research Institute.

\section{Conflicts of interest}

No conflicts of interest declared. 


\section{References}

1. Oh W. Factors affecting enamel and ceramic wear: a literature review. J Prosthet Dent. 2002;87(4):451-9.

2. Norman RL. Frictional Resistance and Dental prosthetics. J Pros Dent. 1964;14(1):45-51.

3. Katona TR. An engineering analysis of dental occlusion principles. Am J Orthod Dentofacial Orthop. 2009;135(6):696 e1-8; discussion -7.

4. Brandini DA, Trevisan CL, Panzarini SR, Pedrini D. Clinical evaluation of the association between noncarious cervical lesions and occlusal forces. J Prosthet Dent. 2012;108(5):298-303.

5. Aubrey RB. Occlusal objectives in orthodontic treatment. Am J Orthod. 1978;74(2):162-75.

6. Baker KL, Nieberg LG, Weimer AD, Hanna M. Frictional changes in force values caused by saliva substitution. Am J Orthod Dentofacial Orthop. 1987;91(4):316-20.

7. Aguirre A, Mendoza B, Levine MJ, Hatton MN, Douglas WH. In vitro characterization of human salivary lubrication. Arch Oral Biol. 1989;34(8):675-7.

8. Koran A, Craig RG, Tillitson EW. Coefficient of friction of prosthetic tooth materials. J Prosthet Dent. 1972;27(3):269-74.

9. Tillitson EW, Craig RG, Peyton FA. Friction and wear of restorative dental materials. J Dent Res. 1971;50(1):149-54.

10. Craig RG, Powers JM. Wear of dental tissues and materials. Int Dent J. 1976;26(2):121-33.

11. Miller G.R. PJM, Ludema K.C. Frictional behavior and surface failure of dental feldspathic porcelain. Wear. 1975;31(2):307-16.

12. Helms RB, Katona TR, Eckert GJ. Do occlusal contact detection products alter the occlusion? J Oral Rehabil. 2012;39(5):357-63.

13. Katona TR. A mathematical analysis of the role of friction in occlusal trauma. J Prosthet Dent. 2001;86(6):636-43.

14. DeLong R, Douglas WH. Development of an artificial oral environment for the testing of dental restoratives: bi-axial force and movement control. J Dent Res. 1983;62(1):32-6.

15. Katona TR, Isikbay SC, Chen J. An analytical approach to 3D orthodontic load systems. Angle Orthod. 2014.

16. Vissink A, Waterman HA, S-Gravenmade EJ, Panders AK, Vermey A. Rheological properties of saliva substitutes containing mucin, carboxymethylcellulose or polyethylenoxide. J Oral Pathol. 1984;13(1):22-8.

17. Frese C, Frese F, Kuhlmann S, Saure D, Reljic D, Staehle HJ, et al. Effect of endurance training on dental erosion, caries, and saliva. Scand J Med Sci Sports. 2014.

[Type here] 
Table 1. Experimental groups. These groups were used with each of the 3 crown materials (denture, ceramic and stainless steel).

\begin{tabular}{|c|c|c|c|c|c|c|c|c|c|c|c|c|c|c|c|c|}
\hline \multirow{2}{*}{$\begin{array}{l}\text { Occlusion: } \\
\text { Tip }\left(2^{\circ}\right) \text { : }\end{array}$} & \multicolumn{4}{|c|}{ I } & \multicolumn{4}{|c|}{ C-B } & \multicolumn{4}{|c|}{ II } & \multicolumn{4}{|c|}{ III } \\
\hline & V & $M$ & D & B & V & $M$ & D & B & V & $M$ & D & B & V & $M$ & D & B \\
\hline & C1 & C1 & C1 & $\mathrm{C} 1$ & C1 & C1 & $\mathrm{C} 1$ & C1 & C1 & C1 & C1 & C1 & C1 & C1 & C1 & C1 \\
\hline & MS & MS & MS & MS & MS & MS & MS & MS & MS & MS & MS & MS & MS & MS & MS & MS \\
\hline & $\mathrm{C} 2$ & $\mathrm{C} 2$ & $\mathrm{C} 2$ & $\mathrm{C} 2$ & $\mathrm{C} 2$ & $\mathrm{C} 2$ & $\mathrm{C} 2$ & $\mathrm{C} 2$ & $\mathrm{C} 2$ & $\mathrm{C} 2$ & $\mathrm{C} 2$ & $\mathrm{C} 2$ & $\mathrm{C} 2$ & $\mathrm{C} 2$ & $\mathrm{C} 2$ & $\mathrm{C} 2$ \\
\hline & MK & MK & MK & MK & MK & MK & MK & MK & MK & MK & MK & MK & MK & MK & MK & MK \\
\hline & C3 & C3 & C3 & $\mathrm{C} 3$ & C3 & $\mathrm{C} 3$ & C3 & C3 & C3 & C3 & $\mathrm{C} 3$ & C3 & C3 & C3 & $\mathrm{C} 3$ & $\mathrm{C} 3$ \\
\hline & $\mathrm{Oa}$ & $\mathrm{Oa}$ & $\mathrm{Oa}$ & $\mathrm{Oa}$ & $\mathrm{Oa}$ & $\mathrm{Oa}$ & $\mathrm{Oa}$ & $\mathrm{Oa}$ & $\mathrm{Oa}$ & $\mathrm{Oa}$ & $\mathrm{Oa}$ & $\mathrm{Oa}$ & $\mathrm{Oa}$ & $\mathrm{Oa}$ & $\mathrm{Oa}$ & $\mathrm{Oa}$ \\
\hline & $\mathrm{C} 4$ & $\mathrm{C} 4$ & $\mathrm{C} 4$ & $\mathrm{C} 4$ & $\mathrm{C} 4$ & $\mathrm{C} 4$ & $\mathrm{C} 4$ & $\mathrm{C} 4$ & $\mathrm{C} 4$ & $\mathrm{C} 4$ & $\mathrm{C} 4$ & $\mathrm{C} 4$ & C4 & $\mathrm{C} 4$ & $\mathrm{C} 4$ & $\mathrm{C} 4$ \\
\hline & $\mathrm{HS}$ & HS & HS & HS & $\mathrm{HS}$ & HS & HS & HS & $\mathrm{HS}$ & HS & HS & HS & HS & HS & HS & HS \\
\hline & C5 & C5 & C5 & C5 & C5 & C5 & C5 & C5 & C5 & C5 & C5 & C5 & C5 & C5 & C5 & C5 \\
\hline
\end{tabular}

Tip: $\quad V=\operatorname{Vertical}\left(0^{\circ}\right) \quad M=$ Mesial $\quad D=$ Distal $\quad B=$ Buccal

C1-5: Controls 1 through 5

Salivas: $\quad M S=$ Moi-Stir $\quad M K=$ Mouth Kote $\quad \mathrm{Oa}=$ Oasis $\quad H S=$ Human Saliva 
Table 2. Absolute Fold Change (AFC) for wet versus dry surface ("All" refers to denture + ceramic $+\mathrm{SS}$.)

\begin{tabular}{|c|c|c|c|c|}
\hline Saliva & Tooth & $\mathrm{n}$ & $\begin{array}{l}\text { AFC for } F_{x} \\
\text { Mean (SE) }\end{array}$ & $\begin{array}{l}\text { AFC for } F_{y} \\
\text { Mean (SE) }\end{array}$ \\
\hline \multirow[t]{4}{*}{ Human } & All & 48 & $0.17(0.03)$ & $0.09(0.03)$ \\
\hline & Denture & 16 & $0.09(0.02)$ & $0.03(0.01)$ \\
\hline & Ceramic & 16 & $0.31(0.09)$ & $0.19(0.08)$ \\
\hline & SS & 16 & $0.10(0.03)$ & $0.04(0.02)$ \\
\hline \multirow[t]{4}{*}{ Moi-Stir } & All & 48 & $0.37(0.19)$ & $0.12(0.04)$ \\
\hline & Denture & 16 & $0.03(0.01)$ & $0.12(0.10)$ \\
\hline & Ceramic & 16 & $0.79(0.52)$ & $0.15(0.08)$ \\
\hline & SS & 16 & $0.29(0.21)$ & $0.09(0.04)$ \\
\hline \multirow[t]{4}{*}{ Mouth-Kote } & All & 48 & $0.15(0.04)$ & $0.25(0.17)$ \\
\hline & Denture & 16 & $0.04(0.01)$ & $0.53(0.51)$ \\
\hline & Ceramic & 16 & $0.30(0.11)$ & $0.19(0.10)$ \\
\hline & SS & 16 & $0.11(0.04)$ & $0.04(0.02)$ \\
\hline \multirow[t]{4}{*}{ Oasis } & All & 48 & $0.13(0.02)$ & $0.14(0.08)$ \\
\hline & Denture & 16 & $0.13(0.04)$ & $0.27(0.22)$ \\
\hline & Ceramic & 16 & $0.14(0.05)$ & $0.09(0.04)$ \\
\hline & SS & 16 & $0.12(0.04)$ & $0.06(0.01)$ \\
\hline
\end{tabular}

All $P<0.0001$ 
Table 3. Comparisons of saliva pairs for each restorative material

\begin{tabular}{|c|c|c|c|c|}
\hline Tooth & AFC for $F_{x}$ & P-Value & AFC for $F_{y}$ & P-Value \\
\hline \multirow[t]{6}{*}{ Denture } & Human > Moi-Stir & $0.0011^{*}$ & Human \& Moi-Stir & 0.3571 \\
\hline & Human > Mouth-Kote & $0.0300^{*}$ & Human \& Mouth-Kote & 0.4365 \\
\hline & Human \& Oasis & 0.1773 & Human \& Oasis & 0.0617 \\
\hline & Moi-Stir \& Mouth-Kote & 0.2571 & Moi-Stir \& Mouth-Kote & 0.8859 \\
\hline & Moi-Stir < Oasis & $0.0000^{*}$ & Moi-Stir < Oasis & $0.0057^{*}$ \\
\hline & Mouth-Kote < Oasis & $0.0005^{*}$ & Mouth-Kote < Oasis & $0.0086^{*}$ \\
\hline \multirow[t]{6}{*}{ Ceramic } & Human \& Moi-Stir & 0.4310 & Human \& Moi-Stir & 0.2585 \\
\hline & Human \& Mouth-Kote & 0.4043 & Human \& Mouth-Kote & 0.4246 \\
\hline & Human > Oasis & $0.0005^{*}$ & Human $>$ Oasis & $0.0002^{*}$ \\
\hline & Moi-Stir \& Mouth-Kote & 0.9628 & Moi-Stir \& Mouth-Kote & 0.7891 \\
\hline & Moi-Stir > Oasis & $0.0058 *$ & Moi-Stir > Oasis & $0.0085^{\star}$ \\
\hline & Mouth-Kote $>$ Oasis & $0.0067^{*}$ & Mouth-Kote $>$ Oasis & $0.0032^{*}$ \\
\hline \multirow[t]{6}{*}{ SS } & Human \& Moi-Stir & 0.7715 & Human \& Moi-Stir & 0.9428 \\
\hline & Human \& Mouth-Kote & 0.8114 & Human \& Mouth-Kote & 0.1271 \\
\hline & Human \& Oasis & 0.6042 & Human \& Oasis & 0.4735 \\
\hline & Moi-Stir \& Mouth-Kote & 0.5970 & Moi-Stir \& Mouth-Kote & 0.1104 \\
\hline & Moi-Stir \& Oasis & 0.4190 & Moi-Stir \& Oasis & 0.5188 \\
\hline & Mouth-Kote \& Oasis & 0.7794 & Mouth-Kote < Oasis & $0.0258^{*}$ \\
\hline
\end{tabular}




\section{FIGURE LEGENDS}

Fig. 1. Testing apparatus. (A) Maxillary tipping is exaggerated for illustrative purposes. (B) The load cell.

Fig. 2. Diagram of forces and moments measured by the load cell. (Moment directions are defined by the right-hand-rule.)

Fig. 3. The 4 molar relationships. (A) Class I, (B) Class I crossbite, (C) Class II and (D) Class III. A \& B are illustrated with the denture teeth, while $C$ and D show the ceramic and the stainless steel crowns, respectively. 


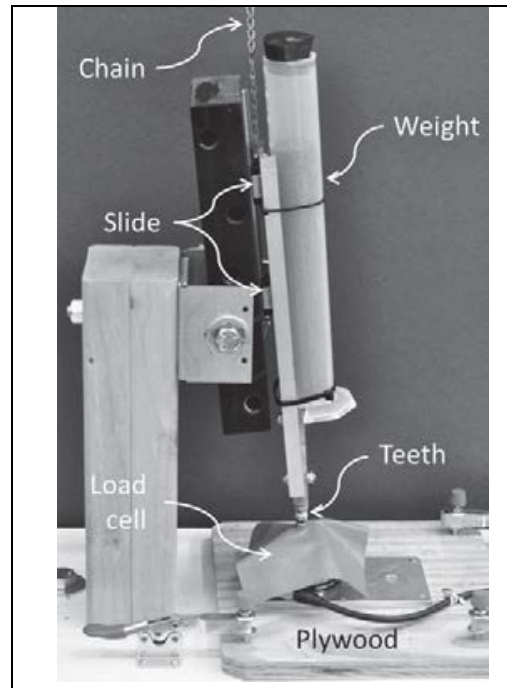

Fig. 1a

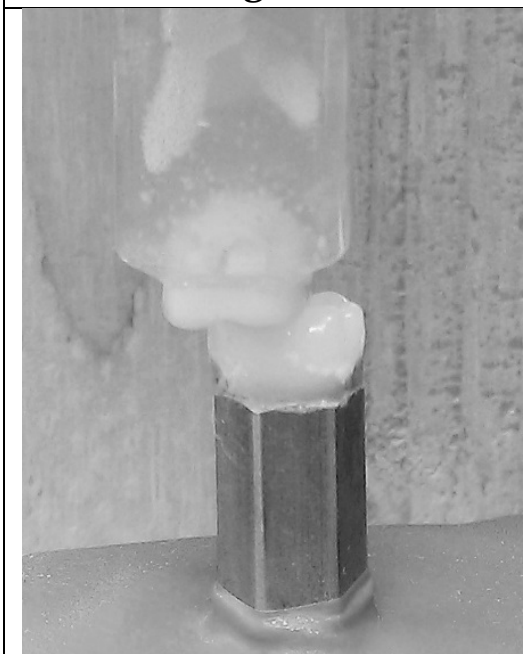

Fig. 3a

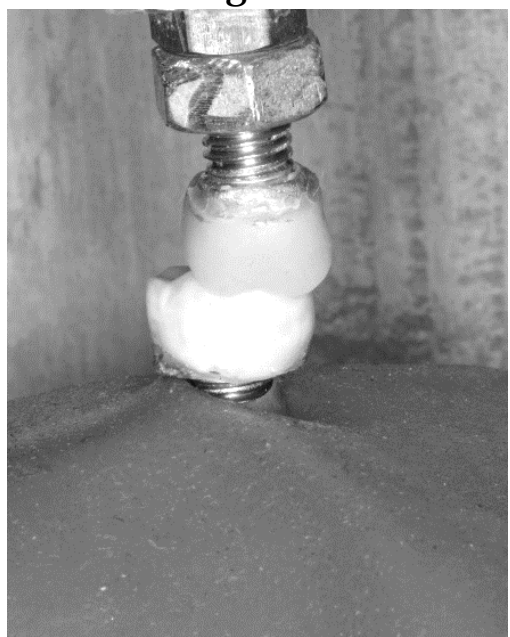

Fig. 3c

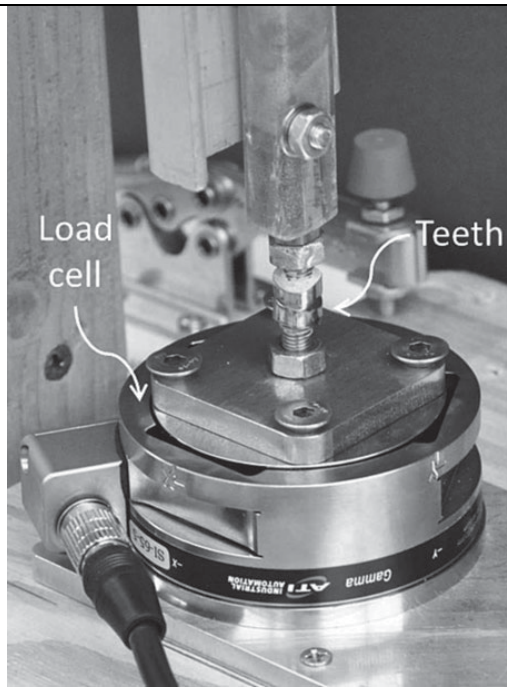

Fig. 1b

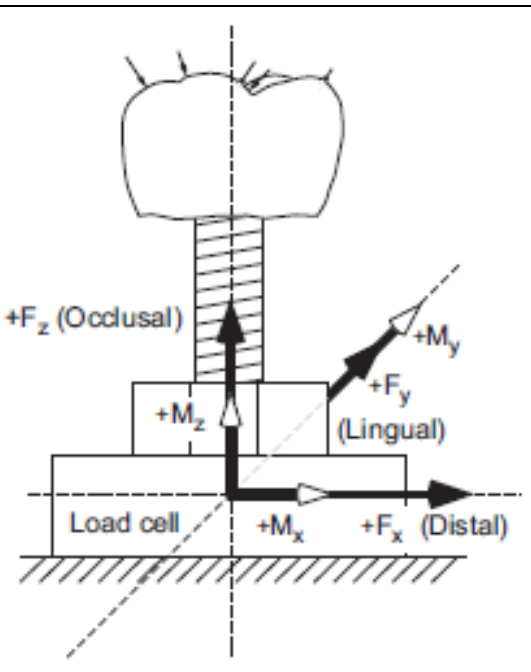

Fig. 2

\section{Fig. 3b}

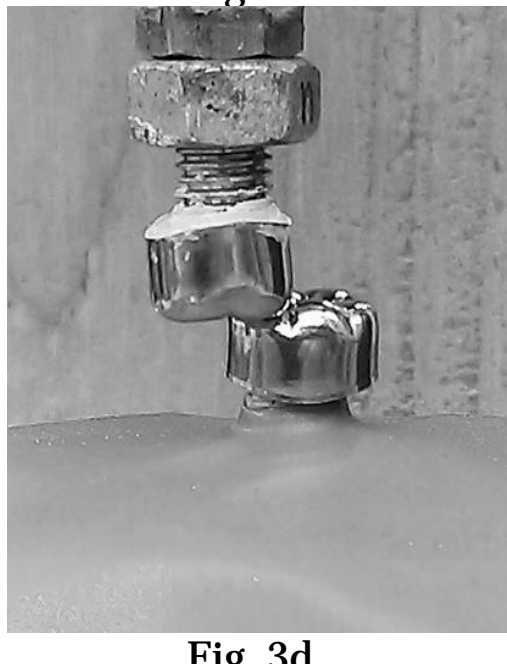

